\title{
The diagnosis and treatment of primary vitreoretinal lymphoma: a review
}

\author{
Jose S. Pulido ${ }^{1,3^{*}}$, Patrick B. Johnston², Grzegorz S. Nowakowski², Alessia Castellino ${ }^{2}$ and Harish Raja ${ }^{1}$
}

\begin{abstract}
Background: To describe the recent diagnostic and treatment options for the most predominant form of primary vitreoretinal lymphoma (PVRL), namely diffuse large B cell lymphoma. This is mainly based on the experience at the Mayo Clinic as well as a partial review of the literature. MYD88 L265P mutation is seen in about 80\% of cases; therefore, a polymerase chain reaction for this mutation helps in making the diagnosis that has been notoriously difficult to make. Local therapy using intravitreal methotrexate and rituximab has been very helpful in the treatment of the local disease. Systemic high-dose intravenous methotrexate is helpful in treating bilateral disease in conjunction with intravitreal therapy. Whether it is helpful in preventing or delaying the development of central nervous system lymphoma (CNSL) is still in dispute. If there is development of CNSL or recurrent ocular disease, alternatives to highdose methotrexate under investigation include pomalidomide, stem cell transplantation, or ibrutinib, with or without local therapy. Vitrectomy alone might be helpful as a debulking procedure. Because of the risks of redevelopment of disease, local radiation should be given if other options are not possible. Aqueous levels of IL10 are helpful in following the redevelopment of local disease.
\end{abstract}

Conclusion: Although PVRL is still a difficult disease to diagnose and treat, new advances are helping to make these easier. Larger collaborative studies will be helpful in determining better treatments.

Keywords: Vitreoretinal lymphoma, Diffuse B cell lymphoma, MYD88 L265P, Ibrutinib

\section{Background}

Primary vitreoretinal lymphoma (PVRL) is a great masquerader and, many times, has been first considered to be uveitis before the final correct diagnosis was made. In the 1980s and 1990s, PVRL was called reticulum cell sarcoma. It was thought to be very malignant, and mortality was very high with median survival of less than 1 year $[1,2]$.

Unfortunately in the literature, PVRL has sometimes not been well-distinguished from other forms of intraocular lymphomatous involvement, causing confusion between the treatments amongst the different forms of intraocular lymphoma.

Intraocular lymphomas can be separated into vitreoretinal lymphomas, choroidal lymphomas, and iridial lymphomas [3]. Vitreoretinal lymphomas (VRL) may

\footnotetext{
${ }^{*}$ Correspondence: pulido.jose@mayo.edu

${ }^{1}$ Department of Ophthalmology, Mayo Clinic, 200 First Street, SW, Rochester, MN 55905, USA

Full list of author information is available at the end of the article
}

then be subdivided into primary or secondary. Secondary VRL are associated with systemic lymphomas elsewhere either in the body, especially in the testes since it also is an immune privileged site or the brain [4]. Only a minority of cases of PVRL are T cell lymphomas, and the other 95\% are diffuse large B cell lymphomas (DLBCL) [3, 5-7]. The cells in DLBCL are CD20 +, which is helpful in diagnosis as well as in consideration of treatment.

Choroidal lymphomas differ from vitreoretinal lymphomas. As opposed to VRL cells, which are present in the vitreous, the subretinal space anterior to Bruch's membrane and in the retina, choroidal lymphomas do not penetrate through Bruch's membrane and, thus, are present posterior to Bruch's membrane [8].

This is important since VRLs are protected by the blood-retinal barrier while choroidal lymphomas are not. Additionally, primary choroidal lymphomas tend to be low-grade B cell lymphomas, typically marginal zone B-cell lymphomas, though some rare cases are choroidal

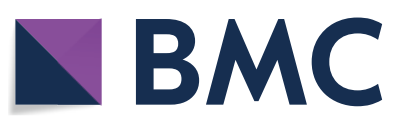

(c) The Author(s) 2018, corrected publication June 2018. This article is distributed under the terms of the Creative Commons Attribution 4.0 International License (http://creativecommons.org/licenses/by/4.0/), which permits unrestricted use, distribution, and reproduction in any medium, provided you give appropriate credit to the original author(s) and the source, provide a link to the Creative Commons license, and indicate if changes were made. The Creative Commons Public Domain Dedication waiver (http:// creativecommons.org/publicdomain/zero/1.0/) applies to the data made available in this article, unless otherwise stated. 
DLBCL [9]. Iridial lymphomas tend to be diffuse large B cell lymphomas [10].

\section{Diagnosis}

Through the years, the diagnosis of PVRL has been very difficult and, thus, treatment has been delayed. The delay has caused some patients to develop central nervous system (CNS) involvement, resulting in the need for systemic treatment $[11,12]$. On average, it takes 3 months between the initial CNS symptoms and the diagnosis of CNS lymphoma [11]. In contrast, for PVRL, on average, it takes over 1 year between symptom onset and the diagnosis of PVRL $[11,13]$.

In this time period, it is common for the patient to have had multiple eye examinations. They have been considered to have uveitis (ocular inflammation) and, many times, have been treated with corticosteroids. Since corticosteroids are lympholytic, there is a transient beneficial effect; therefore, the ultimate diagnosis is further delayed. In addition, if the corticosteroids are given before a vitreous biopsy, fragile diffuse large B cells are lysed, further delaying the ultimate diagnosis.

To make a diagnosis, it is important to determine the region of the eye with the most cellular involvement with lymphoma. The anterior chamber rarely has many cells; therefore, sampling of the anterior chamber is not usually advised. The eye that has the most vitreous cells should be biopsied; and if the patient has been placed on systemic or local corticosteroids, it is best to wait a few weeks to allow more of a vitreal infiltration before doing a vitreous biopsy. In the meantime, if an MRI (magnetic resonance imaging) of the brain has not been done in the last 2-3 months, it should be performed a few weeks after stopping the corticosteroids to make sure no CNS lesion has developed (Fig. 1). With small-gauge vitrectomy instruments, the risks of the vitreous biopsy have been decreased significantly. It is still important to close the sclerotomies with an absorbable suture to avoid the possibility of cells leaking out. In addition, valved trocars should be used for the same reason. Obtaining a good
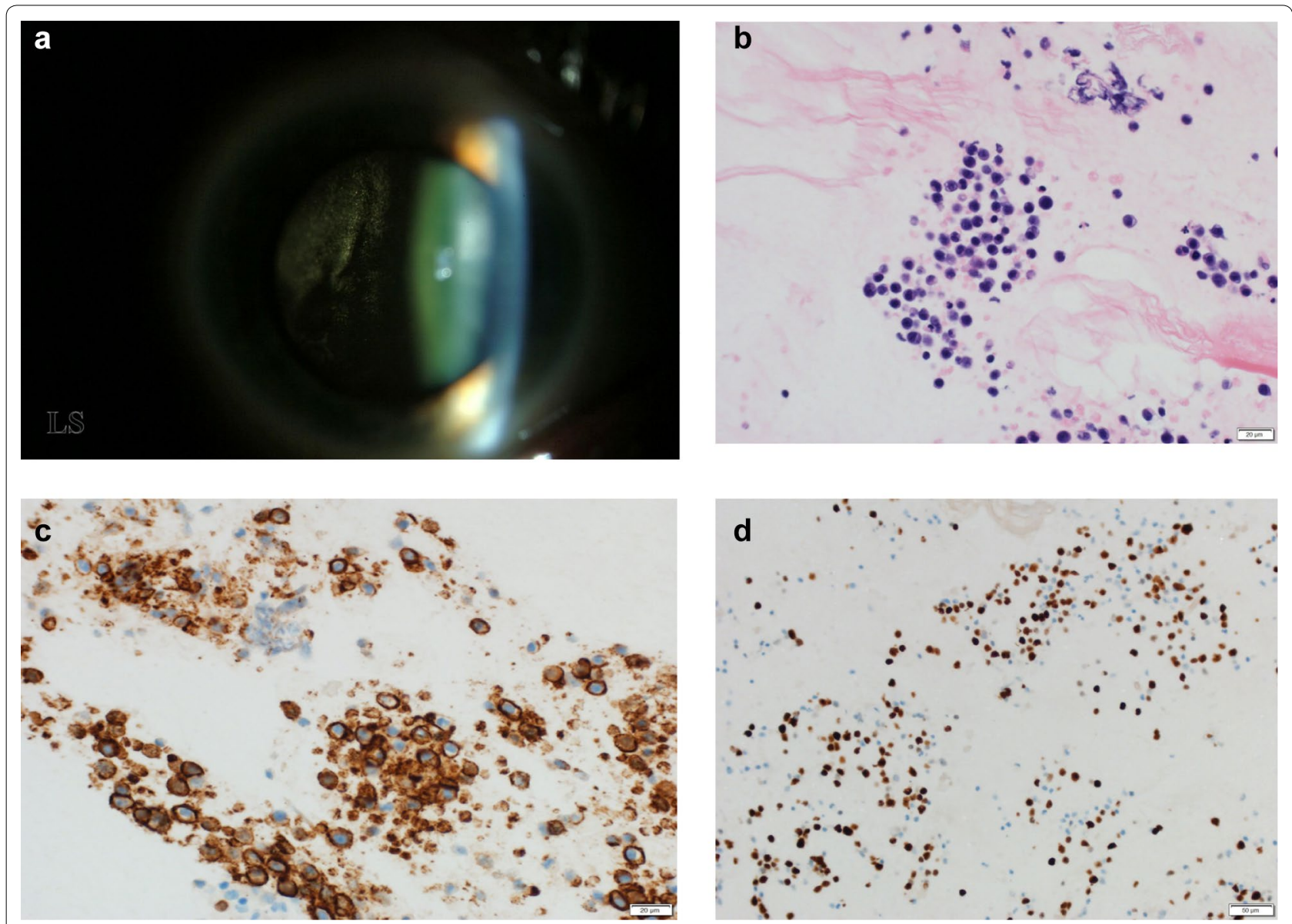

Fig. 1 Diffuse large B cell lymphoma in the vitreous of a patient (a). Cytomorphology of the vitreoretinal diffuse large B cell lymphoma cells (H\&E $\times 400$ - photograph thanks to Diva Salomao, MD (b). Immunostaining for CD20 of the vitreoretinal lymphoma cells $(\times 400)(\mathbf{c})$. Ki-67 staining of the vitreoretinal cells; note the extensive staining which is consistent of marked local replication $(\times 200)(\mathbf{d})$ 
vitreous biopsy is critical. Two methods can be utilized. In both, a cut rate of about 600 cuts per minute with a 25 -gauge vitrector is used. A 12-cc syringe and manual aspiration can be used, and a wide-field viewing method is very helpful. In one method, air is infused while the vitreous is removed. About $2 \mathrm{cc}$ of pure vitreous can be obtained with this method. In the other, saline infusion is turned on and off, while the vitrector is moved from vitrectomized area to non-vitrectomized area for a 6-cc partially diluted sample to be obtained. It is critical that the pathologist and their laboratory are aware ahead of time that a vitreous sample is being sent for examination for possible PVRL. In addition, having a pathologist who has experience in ocular cytology and histopathology is essential. Many facilities examine cellular pellets with immunohistochemistry to make a diagnosis. It might be that vitrectomy can have an effect in decreasing tumor burden and thus might have a therapeutic effect $[14,15]$.

Elevated serum interleukin 10 (IL10) levels are seen in patients with DLBCL and has been shown to be correlated with shorter event-free survival [16]. The effect of IL10 in the retina is to decrease inflammation and, thus, decreasing leakage through the blood retinal barrier similar to its effect in the nervous system $[17,18]$.

Teleologically, it makes sense that the lymphoma cells would secrete factors that would protect the cells from the immune system. As it is, the cells have honed to the vitreous because it is protected from the immune system. There have been attempts at making the diagnosis by evaluating the interleukin levels in the vitreous or aqueous humor [19].

Interleukin 10 levels or IL 10/IL6 ratios have been used. Interleukin 10 levels tend to be elevated in both the vitreous and aqueous in eyes with vitreoretinal lymphoma $[20,21]$.

Because of variability in the initial IL10 level in the aqueous, it cannot be utilized for making the diagnosis of VRL. There are no definite cut-offs, so the area under the curve of these tests on a ROC (receiver operator characteristic) curve are low [22]. In addition, there is variability in the ELISA (enzyme-linked immunosorbent assay) levels obtained not only from kits from different companies or laboratories but also between one lot and another from the same company. There are variabilities of normal levels, so only a difference of levels using the same lot number by the same company can be used; this is, therefore, only helpful in following treatment results as discussed below [21, 22]. Additionally, there is significant variability between lots of ELISAs, so care must be taken in interpreting the results.

Some investigators have utilized FACS (fluorescenceactivated cell sorting) analysis to look for CD20+cells [23]. Flow cytometry can identify clonality by "gating" for kappa and lambda light chain positivity and dominance. This is often combined with minimal cytomorphology to make a diagnosis of PVRL. However, since there are not many cells in most cases, the use of FACS can quickly exhaust the sample and may not afford a diagnosis. In addition, the $B$ cells in the vitreous tend to be larger and more fragile than in the blood so that analysis of the morphology and the FACS results can be difficult and nondefinitive [24].

Regardless of which of the two methods that the vitreous is obtained, the sample is then diluted with RPMI (Roswell Park Memorial Institute) solution in a 2/1 dilution, and transported immediately on ice to make a cytospin and then a cytoblock. Histology can be performed on the cytoblock to observe the morphology of the cells. Immunostaining of the cells for CD20 and CD3 cells should be performed. Finally, a sample should be sent for an allele-specific PCR (polymerase chain reaction) for the MYD88 L265P mutation that is seen in 60 to $80 \%$ of cases of vitreoretinal lymphoma [25-28]. This test can be ordered from the Mayo Clinic labs or any other CLIAapproved laboratory that offers this test. The clinician should call ahead of doing the biopsy to make sure that the laboratory will take the sample and to find out how the sample should be handled.

If the MYD88 allele-specific PCR is positive in the context of CD20 + cells in the vitreous, a diagnosis of vitreoretinal lymphoma can be confirmed. PCR for monoclonal $\mathrm{B}$ cell rearrangement can also be done, but more cells are required and IGH rearrangement can have a high falsenegative rate; in addition, it requires many more cells than MYD88 L265P mutation testing. Finally, it is much more subjective than the MYD88 testing $[25,29]$.

If the biopsy is nondiagnostic and there is still strong suspicion of vitreoretinal lymphoma, then the other vitreous should be biopsied; or if there are aggregates of subretinal cells, a retinal biopsy using the same vitrector technique of a lower cut rate and manual aspiration should be done (Fig. 2). Choroidal biopsy is not required since the cells all reside anterior to Bruch's membrane. Endolaser around the biopsy site can be done as well; however, it should be at the discretion of the surgeon.

Targeted next-generation sequencing (NGS) on small volumes of vitrectomy fluid has promise in aiding the diagnosis of PVRL. A recent publication examined small fluid volumes from four patients with suspected or known VRL and performed NGS spanning 126 genes [30]. Gain-of-function mutations in the MYD88 oncogene were detected including the L265P encoding mutation, as well as a mutation encoding an S243 N mutation. Also identified were losses in the tumor suppressor CDKN2A gene in all four cases and a single copy loss in one sample encoding the tumor suppressor PTEN. 

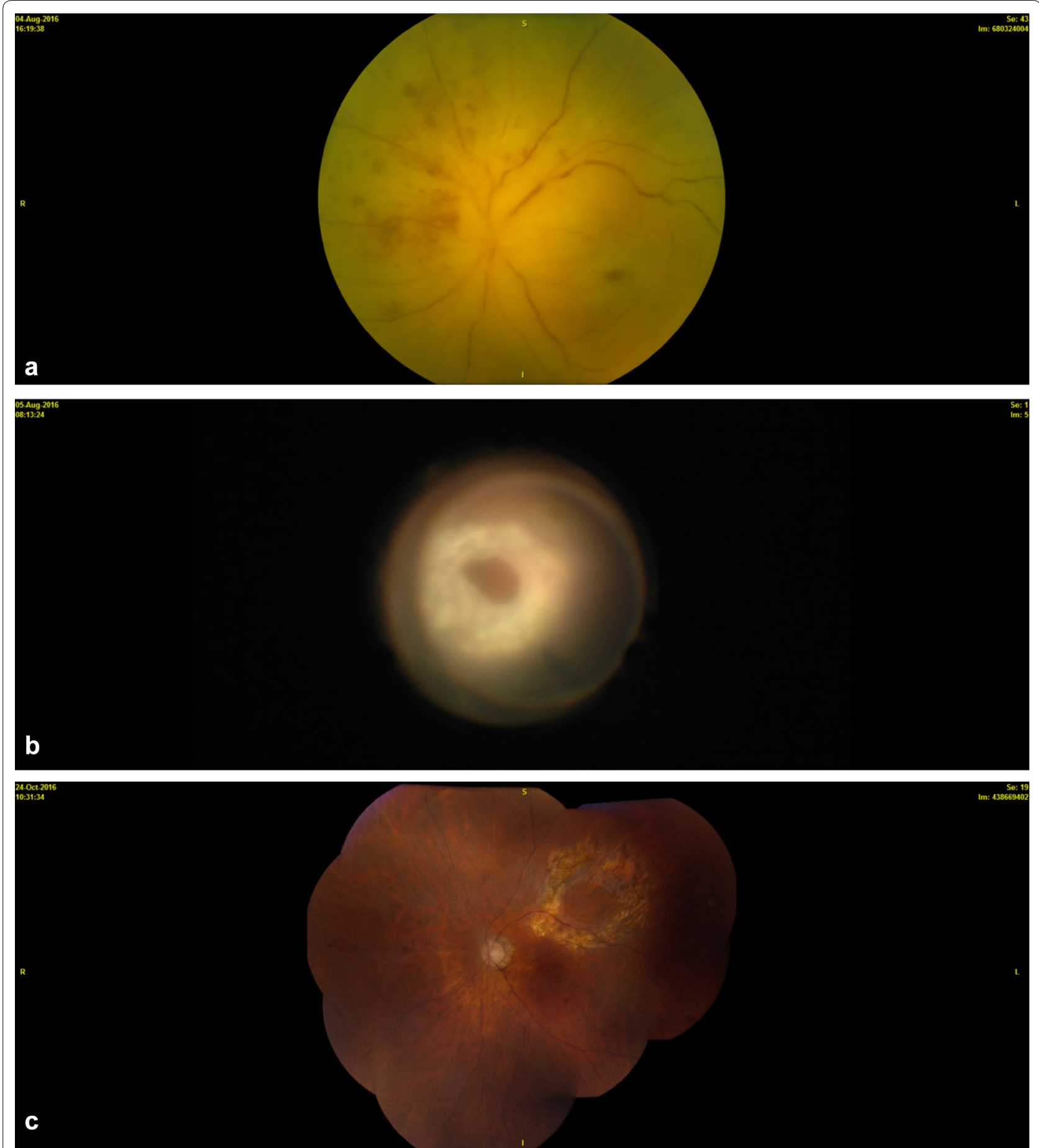

Fig. 2 Creamy white retinal involvement by vitreoretinal lymphoma was suspected (a) and a vitrector was used to make the diagnosis (b). Final photograph following biopsy and treatment with intravitreal methotrexate and rituximab therapy and systemic therapy with ibrutinib (c) 
Addition of this technology will likely enable more rapid diagnosis of PVRL.

\section{Treatment PCNSL}

Considering the similarity between PVRL and PCNSL as well as how much more prevalent is PCNSL, it is worth reviewing the treatments of PCNSL. The possibilities include whole-brain radiotherapy (WBRT), chemotherapy, WBRT and chemotherapy, or high-dose chemotherapy with stem cell therapy (HDT with SCT). WBRT was used in RTOG (Radiation Treatment Oncology Group) 8315 with $36-40$ Gy to the whole brain plus a 20-Gy boost to the tumor as well as 2-cm margin around the tumor [31]. It was a phase II trial with 41 patients. The overall rate of remission (ORR) was $90 \%$, with a complete remission of $55 \%$ and partial remission of $35 \%$. The median was 12.2 months, and $61 \%$ had brain relapse. High-dose methotrexate at $8 \mathrm{mg} / \mathrm{m}(\mathrm{e}) 2$ (meters squared) has a 55.4-month overall survival rate [32, 33]. For HDT with HSCT (high-dose therapy with hematopoietic stem cell transplantation), the first trial had mildly impressive results [34]. This study used MTX at $3.5 \mathrm{mg} / \mathrm{m}(\mathrm{e}) \mathrm{e}) 2$ plus cytosine arabinoside (ARA C) and Cytoxan followed by BEAM [(BiCNU) carmustine, etoposide, ARA-C-cytarabine, melphalan)] conditioning and allograft stem cell. There were 28 patients enrolled but only 14 proceeding to transplant. The median follow-up was 9.3 months. The compete response rate was only $18 \%$, and the median event-free survival was 9 months. Another phase II clinical trial utilized MTX induction, followed by ARA C and then chemo-mobilization, followed by high-dose therapy with Carmustine/Thiotepa and then autologous transplant [35]. The overall survival at 5 years was $69 \%$ for all patients and $87 \%$ for those that were able to have a bone marrow transplant (BMT).

A more recent study, CALGB 50202, used induction chemotherapy with MT-R: methotrexate (MTX), temozolomide, rituximab with intravenous HD-MTX $(8 \mathrm{gm} /$ $\mathrm{m}^{2}$ ) administered every 2 weeks $\times 8$ and rituximab administered weekly $\times 6$. Temozolomide $(150-200 \mathrm{mg} /$ $\mathrm{m}^{2}$ ) was administered starting on day +7 and continued for 5 days and was repeated every 28 days. The patients who achieved a complete response then received intensive consolidation with cytarabine $2 \mathrm{gm} / \mathrm{m}^{2}$ BID on days 1-4 with infusional etoposide $40 \mathrm{mg} / \mathrm{kg}$ over $96 \mathrm{~h}$ (EA). A total of 46 patients were treated. The median progression-free survival (PFS) was 2.3 years, and the estimated PFS with 95\% confidence limits at 1,2 , and 3 years were $0.64(0.48,0.76), 0.55(0.39,0.69)$, and $0.50(0.33,0.64)$, respectively. The estimated overall survival (OS) with $95 \%$ confidence limits at 1,2 , and 3 years was $0.73(0.58$, $0.84), 0.71(0.55,0.81)$ and $0.67(0.51,0.79)$, respectively.
Thus, the rates of PFS and OS in newly diagnosed PCNSL patients were at least comparable to combined modality treatment that involves reduced or standard doses of whole-brain irradiation. The MT-R-EA regimen was well-tolerated in patients age $>60$ and has similar efficacy in this population as in younger patients.

In summary, it appears that high-dose MTX based therapy is beneficial in PCNSL. Stem cell transplantation may provide therapeutic benefit as well, but further studies are required.

\section{PVRL}

Once the diagnosis of vitreoretinal lymphoma has been made, it is important to confirm that there is only ocular involvement. In the absence of systemic involvement, the question arises as to whether one eye or both eyes are involved. If there is unilateral involvement, then local therapy should be considered. It has been shown that there is no difference in recurrence rate if standard local therapy or systemic therapy is used, though there might be some difference in mortality if treatment is started earlier; but the data for that is retrospective and not definitive [12, 36, 37].

Traditionally, local therapy involved external beam radiotherapy. Up to $54 \mathrm{~Gy}$ has been given, but the amount that has been used has been decreased as cases of radiation retinopathy have developed [38]. Most recently, 30-36 Gy have been used; but even at these levels, radiation retinopathy can develop. Kaushik et al. have shown that at even levels of $20 \mathrm{~Gy}$, radiation retinopathy can develop [39].

Since the patients now are living longer than in the 1980-1990 s, there will be more cases of subsequent radiation retinopathy. We are in the process of looking at our data, and we have found that over the last 28 years, we have treated over 70 patients that have had primary or secondary vitreoretinal lymphoma. The overall survival of patients with vitreoretinal lymphoma is now over 7 years, so whatever treatment is performed, one has to consider that these patients are living longer. Therefore, we utilize radiation primarily as salvage therapy. It should be noted, however, that others feel comfortable with the use of a median of 36 Gy [37]. The authors acknowledged that the radiated patients will all develop cataracts. In their series of 11 patients, only one eye in a patient who had diabetes developed radiation retinopathy, but another patient developed severe bilateral optic nerve atrophy. The median follow-up was 42 months, and three patients of the 11 developed recurrent intraocular disease. Several patients did not have the cataracts removed, so it is unclear if the cataract was too dense to not allow good visualization of the retina and, thus, mild retinopathy could have been missed. In addition, the treatment or 
outcome following the recurrent ocular disease is unclear, and no mention is made regarding the total incidence of recurrence either in the eye or brain. Weekly methotrexate $(400$ micrograms in $0.1 \mathrm{cc}$ ) injected into the vitreous cavity (intravitreal methotrexate) and was shown by Fishburne to be useful in the treatment of VRL [40]. Others have verified this finding [41]. The problem is that it takes on average 6.4 methotrexate injections to develop a remission [41]. If intravitreal methotrexate will be used, it is critical that it is the intrathecal form and that the right concentration $(400 \mathrm{mcg} / 0.1 \mathrm{cc}$ ) be used. In addition, it is important that a paracentesis first be performed because that will decrease the chances of subconjunctival extravasation of the methotrexate. Subconjunctival extravasation causes severe irritation and pain for about 1 day. It can also result in corneal keratopathy. The aqueous paracentesis fluid can be frozen and evaluated for interleukin 10 levels to determine response to therapy [22].

In 2007, we reported the ocular toxicity studies of intravitreal rituximab [42]. We showed that $1 \mathrm{mg}$ of intravitreal rituximab in $0.1 \mathrm{cc}$ (the $10 \mathrm{mg} / \mathrm{cc}$ concentration) not only was safe but also could treat vitreoretinal lymphoma. This was then confirmed by others [43-45]. There are no set protocols that have been verified in larger cohorts of patients. It is important to realize as well that these patients have a high chance of local recurrence or CNS spread [12], so careful follow-up is necessary.

Traditionally, determining if there is a subtle increase in the lymphomatous cells in the vitreous between one visit and the next was the method to detect a local recurrence. Unfortunately, from 1 month to another, slight changes in the amount of vitreous cells are difficult to ascertain. We and others have shown that following the change of interleukin 10 levels in the anterior chamber is a good way to determine if the eye remains in remission [22]. Performing a paracentesis of the anterior chamber is relatively easy, and rising IL10 levels indicate the start of a local recurrence. Resuming frequent therapeutic injections (as described below) keeps the IL 10 levels in abeyance.

In the absence of large studies, for cases of monocular VRL involvement, a combination of intravitreal methotrexate and rituximab is our first line treatment. A paracentesis is performed, and the fluid is placed on dry ice and sent immediately for determination of IL10 levels. The intravitreal methotrexate is then injected, since the pressure in the eye is lowest at this point and there would be less chances of reflux. Rituximab is then injected, since a little reflux of rituximab is innocuous. During the first month, injections are performed weekly, but only the first paracentesis fluid is tested for IL10 levels. The following month, the paracentesis is again sent and, assuming that there is a decrease in IL10 levels, the injections are done every other week. In the subsequent month, levels are checked again; and if at a low level, then injections are only performed monthly. Alternatively, levels are checked and no injections are done until the IL10 levels start to rise, and then more frequent injections are resumed. The contralateral eye has to be visualized monthly to verify that it is not involved, and MRI of the brain is performed every 3 months for the first 2 years and then every 6 months, thereafter.

Again, for those patients with bilateral eye involvement, there is not an established treatment regimen. The use of bilateral radiation should be avoided because of a high probability of recurrence [12]. Systemic therapy should be considered in this situation. One regimen involves intravenous methotrexate $\left(8 \mathrm{gm} / \mathrm{m}^{2}\right.$ every 2 weeks initially) combined with administration of intravitreal rituximab and methotrexate. We utilize at least one series of intravitreal methotrexate and rituximab to help clear the vitreous. Again, IL10 levels in the aqueous are useful to evaluate on a monthly basis to make sure that there is no evidence of elevation. In addition, MRI of the brain every 3 months should be performed for the first 2 years.

The group that used bilateral radiation as discussed above also gave systemic therapy. We do not know the overall incidence of recurrence, but we do know that of 11 patients, 3 had ocular recurrence during a median of 42 months of follow-up. Their treatment protocol was treatment with R-MPV (rituximab $375 \mathrm{mg} / \mathrm{m}^{2}$ intravenously (IV) on day one, methotrexate $3.5 \mathrm{~g} / \mathrm{m}^{2}$ IV over $2 \mathrm{~h}$ on day one followed by leucovorin rescue, procarbazine $100 \mathrm{mg} / \mathrm{m}^{2} /$ day orally for 7 days with odd cycles only, and vincristine $1.4 \mathrm{mg} / \mathrm{m}^{2}$ capped at $2 \mathrm{mg}$ IV on day one) given every 2 weeks for five cycles. RT was started a minimum of 2 weeks after the last cycle of methotrexate and targeted the bilateral orbits, including the entire globes. At least 1 month after the completion of RT, two cycles of rituximab $\left(375 \mathrm{mg} / \mathrm{m}^{2}\right.$ IV on day one) and cytarabine $\left(3 \mathrm{~g} / \mathrm{m}^{2}\right.$ IV over $3 \mathrm{~h}$ once daily on days one and two) were administered on two occasions, 2 weeks apart. Intrathecal (IT) methotrexate (12 mg intrathecal or $6 \mathrm{mg}$ by Ommaya reservoir) or cytarabine ( $100 \mathrm{mg}$ intrathecal) was typically administered once per cycle. We do not feel that Omaya reservoirs are needed or should be used.

\section{Emerging therapies \\ Stem cell transplantation}

There exists limited data on the use of high-dose chemotherapy and autologous stem cell transplantation in the treatment of PVRL, with most trials either including only PCNSL or combining PCNSL with PVRL. The following two studies included only patients with PCNSL: In 2003, a publication from Memorial Sloan Kettering described 28 patients with PCNSL who underwent intravenous methotrexate and Ara-C followed by BEAM conditioning 
chemotherapy and autologous stem cell transplantation [12]. The median follow-up was 9.3 months. There was an $18 \%$ complete response rate with a median event-free survival of 9 months. A subsequent study from Germany enrolled 30 patients who were younger than 65 years of age who had had PCNSL. Patients underwent highdose methotrexate induction and ARA-C, then stem cell mobilization, followed by Carmustine and Thiotepa highdose therapy and autologous stem cell transplantation, and then whole brain radiotherapy [35]. Of those that were able to successfully undergo the transplant, there was an $87 \%$ overall survival rate at 5 years. When examining all enrolled patients, including those that could not complete the high-dose methotrexate, there was a $69 \%$ survival rate at 5 years. Other different induction and conditioning regimens in the treatment of PCNSL have been described as well [35, 46, 47].

The use of stem cell transplantation for PVRL has been described [48]. Originally, it was used for refractory or recurrent cases of vitreoretinal and/or CNS lymphoma. The patients that were able to complete the treatment regimen had a median overall survival was 58.6 months compared to 18.3 months for the overall group. The two-year survival rate was $69 \%$ for the transplant group compared to $45 \%$ for the entire group [48]. Other conditioning chemotherapy regimens have been used, but it appears that this might be a reasonable way to treat refractory or recurrent PVRL $[49,50]$.

At the present time, we believe that this is a very reasonable treatment for patients with refractory or recurrent PVRL or PCNSL. Originally, it was used for patients 65 years or younger; the age of the patient is not as important as the systemic health of the patient [48]. Whether high-dose chemotherapy and autologous stem cell transplantation should be incorporated as consolidation in primary treatment of PVRL remains debatable, but it is not unreasonable to consider.

\section{Pomalidomide}

The use of thalidomide-related agents in the treatment of systemic diffuse large B cell lymphoma has been described [51, 52]. Pomalidomide (a similar agent but with better penetration into the CNS) has shown efficacy in an animal model of CNS lymphoma [53]. An ongoing study being conducted at Mayo Clinic sites and DanaFarber Cancer Institute was developed to investigate the use of pomalidomide for refractory or recurrent CNS or vitreoretinal. Enrollment continues with promising results [54].

\section{Ibrutinib}

The fact that the MYD88 L265P mutation is so prevalent in cases of vitreoretinal lymphoma has opened a new possible treatment option. Ibrutinib was originally utilized for the treatment of chronic lymphocytic leukemia (CLL) [55]. It is an oral targeted agent whose mechanism of action is inhibiting Bruton's tyrosine kinase (BTK). In addition, it inhibits the HCK tyrosine kinase protein. Interestingly, both of these pathways are upregulated by the MYD88 L265P mutation [56]. Ibrutinib is approved for the treatment of Waldenström's macroglobulinemia WM [57]. Over $90+\%$ of WM patients have the MYD88 mutation [58]. Recently, it has been shown that ibrutinib has an $80 \%$ response rate for the systemic $(A B C)$ activated B cell form of DLBCL [59].

An interim analysis of a phase II clinical trial utilizing single agent ibrutinib in relapsed or refractory PCNSL and PVRL was recently presented [60]. Eleven patients with PCNSL and seven patients with PVRL at time of study entry were included in the analysis. The median number of treatment cycles was five, with an overall response rate of $56 \%$ and 3 of 18 patients achieving a CR as best response. The FDA has approved ibrutinib for Waldenström's macroglobulinemia. In two patients with WM who subsequently developed VRL followed at the Mayo Clinic, Rochester, MN, we have treated with ibrutinib in a salvage setting with complete remissions in both, however, one developed resistance to the ibrutinib and developed recurrence for which he was resumed on local intravitreal infections (unpublished data). Because of the fact that Waldenström's and primary vitreoretinal lymphoma both have a similar MYD88 mutation, it might be reasonable to use this agent in clinical trials for patients with VRL. The fact that it is orally delivered and that it can penetrate the blood retinal and blood CNS barriers makes it an attractive agent that requires study for vitreoretinal lymphoma [61].

Caution should be taken when incorporating ibrutinib with high-dose steroids, however, as cases of invasive fungal and pneumocystis infections have been reported in this setting $[62,63]$.

\section{Lenalidomide plus rituximab}

A recent abstract presented at the American Society of Hematology Annual Meeting in 2016 from the French LOC Network reviewed results from a phase II trial of lenalidomide plus rituximab for relapsed or refractory PCNSL or PVRL [60]. Of the 45 enrolled patients, 9 patients had PVRL and 10 patients had secondary VRL; 6 of the 19 patients achieved a complete remission. Thus, immunomodulatory agents appear to be very promising in the treatment of VRL.

\section{Vitrectomy}

As mentioned previously, it may be that debulking could have a therapeutic effect as well, though there are only a 
few case reports. At the present time, there is not enough data to consider this as the only therapy, but it might be a useful adjunct in cases with significant cellular load [14, 15].

\section{Summary of therapy by authors}

Figure 3 summarizes our suggestions for vitreoretinal lymphoma. In the presence of PVRL and no evidence of CNS lymphoma, if it is unilateral, then consideration of local intravitreal therapy should be given. If local recurrence occurs again in the absence of bilateral involvement or CNS involvement, either resumption of local intravitreal therapy or local radiation (30 Gy) can be given. If there is bilateral vitreoretinal recurrence and/or CNS involvement, treatment with ASCT can be given in conjunction with local therapy. If the patient is not systemically capable of undergoing stem cell transplantation, systemic therapy with ibrutinib can be considered if there is evidence of MYD88 L265P mutation.

If there is initial bilateral ocular involvement with PVRL then systemic methotrexate, rituximab and temozolomide could be used in conjunction with local intravitreal therapy with rituximab and methotrexate. If there is bilateral recurrence of CNS involvement, ASCT can be considered. If initially there is VRL with CNS involvement, then systemic therapy with methotrexate and rituximab should be given. Local therapy with intravitreal methotrexate and rituximab can be given for the first month as well. If recurrence occurs, transplantation can be done if the patient is less than 70 and is appropriate for high-dose chemotherapy and stem cell transplantation. If the patient is older or in poor health and if the cells have the MYD88 L265P mutation, besides local therapy, systemic ibrutinib can be considered.

\section{Conclusions}

Many advances in the detection and diagnosis of PVRL have been made in the recent past with new technologies such as NGS developing in our diagnostic armamentarium. Although historically, very limited treatment options existed for PVRL, new therapeutic options, including intravitreal therapy, systemic

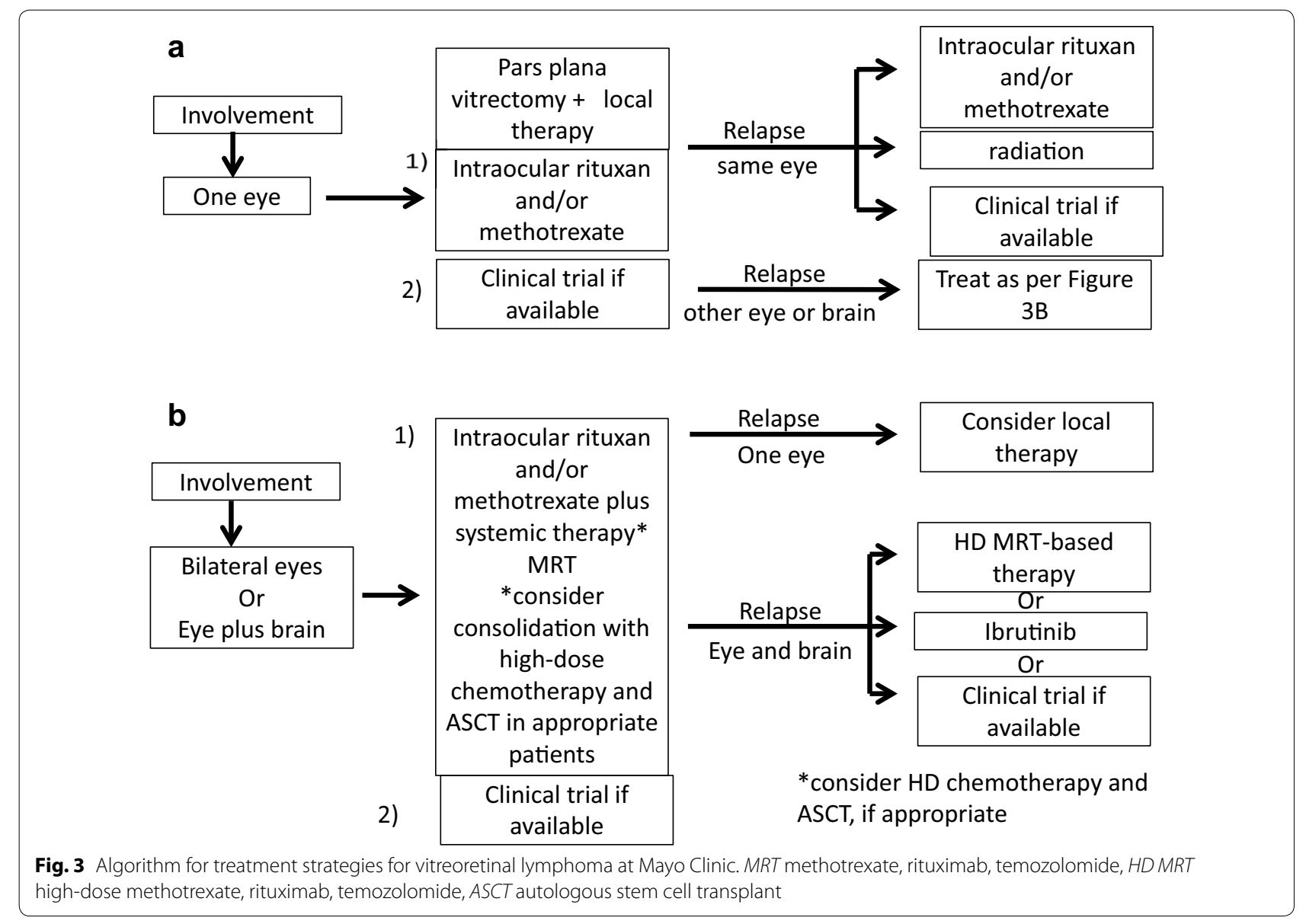


chemotherapy, and immunomodulatory agents are changing the landscape of treatment options for this rare disease.

\section{Authors' contributions}

All five authors have done research about vitreoretinal disease and have contributed to the thought, writing, and concepts in this manuscript. All authors read and approved the final manuscript.

\section{Author details}

${ }^{1}$ Department of Ophthalmology, Mayo Clinic, 200 First Street, SW, Rochester, MN 55905, USA. ${ }^{2}$ Departments of Hematology, Mayo Clinic, Rochester, MN, USA. ${ }^{3}$ Department of Molecular Medicine, Mayo Clinic, 200 First Street, SW, Rochester, MN 55905, USA

\section{Acknowledgements}

We are grateful for the manuscript formatting by Mrs. Denise Chase.

\section{Competing interests}

The authors declare that they have no competing interests. Jose Pulido, MD owns stock in LAgen laboratories that supplies induced pluripotent stem cellderived retinal pigment epithelium cells for laboratory use only.

\section{Availability of data and materials}

All authors were involved in the development of the manuscript.

\section{Consent for publication}

This is a review so consent is not applicable.

\section{Ethics approval and consent to participate}

This is a review so ethics review is not applicable.

\section{Funding}

Supported in part by unrestricted grants from Research to Prevent Blindness, Inc., the Deshong family, and the Paul family.

\section{Publisher's Note}

Springer Nature remains neutral with regard to jurisdictional claims in published maps and institutional affiliations.

Received: 3 January 2018 Accepted: 16 April 2018

Published online: 07 May 2018

\section{References}

1. Barr CC, Green WR, Payne JW, Knox DL, Jensen AD, Thompson RL. Intraocular reticulum-cell sarcoma: clinico-pathologic study of four cases and review of the literature. Surv Ophthalmol. 1975;19:224-39.

2. Kaplan HJ, Meredith TA, Aaberg TM, Keller RH. Reclassification of intraocular reticulum cell sarcoma (histiocytic lymphoma). Immunologic characterization of vitreous cells. Arch Ophthalmol. 1980;98:707-10.

3. Gunduz K, Pulido JS, McCannel CA, O'Neill BP. Ocular manifestations and treatment of central nervous system lymphomas. Neurosurg Focus. 2006;21:E9.

4. Salomao DR, Pulido JS, Johnston PB, Canal-Fontcuberta I, Feldman AL. Vitreoretinal presentation of secondary large B-cell lymphoma in patients with systemic lymphoma. JAMA Ophthalmol. 2013;131:1151-8. https:// doi.org/10.1001/jamaophthalmol.2013.334.

5. AlQahtani A, Touitou V, Cassoux N, Aknin C, Merle-Beral H, Bodaghi B, et al. More than a masquerade syndrome: atypical presentations of vitreoretinal lymphomas. Ocul Immunol Inflamm. 2014;22:189-96. https ://doi.org/10.3109/09273948.2013.835427.

6. Fend F, Ferreri AJ, Coupland SE. How we diagnose and treat vitreoretinal lymphoma. Br J Haematol. 2016;173:680-92. https://doi.org/10.1111/ bjh. 14025.

7. Coupland SE, Anastassiou G, Bornfeld N, Hummel M, Stein H. Primary intraocular lymphoma of T-cell type: report of a case and review of the literature. Graefes Arch Clin Exp Ophthalmol. 2005;243:189-97. https:// doi.org/10.1007/s00417-004-0890-2.

8. Dolz-Marco R, Gallego-Pinazo R, Jung JJ, Freund KB, Diaz-Llopis M. Sequential multimodal imaging findings in a case of primary vitreoretinal lymphoma. Retin Cases Brief Rep. 2014;8:314-7. https://doi.org/10.1097/ ICB. 0000000000000053

9. Coupland SE, Damato B. Understanding intraocular lymphomas. Clin Exp Ophthalmol. 2008;36:564-78. https://doi.org/10.111 1/j.1442-9071.2008.01843.x.

10. Mashayekhi $A$, Shields $C L$, Shields JA. Iris involvement by lymphoma: a review of 13 cases. Clin Exp Ophthalmol. 2013;41:19-26. https://doi.org/1 0.1111/j.1442-9071.2012.02811.x.

11. Grimm SA, McCannel CA, Omuro AM, Ferreri AJ, Blay JY, Neuwelt EA, et al. Primary CNS lymphoma with intraocular involvement: International PCNSL Collaborative Group Report. Neurology. 2008;71:1355-60. https:// doi.org/10.1212/01.wnl.0000327672.04729.8c.

12. Grimm SA, Pulido JS, Jahnke K, Schiff D, Hall AJ, Shenkier TN, et al. Primary intraocular lymphoma: an International Primary Central Nervous System Lymphoma Collaborative Group Report. Ann Oncol. 2007;18:1851-5. https://doi.org/10.1093/annonc/mdm340.

13. Chan CC, Rubenstein JL, Coupland SE, Davis JL, Harbour JW, Johnston $\mathrm{PB}$, et al. Primary vitreoretinal lymphoma: a report from an International Primary Central Nervous System Lymphoma Collaborative Group symposium. Oncologist. 2011;16:1589-99. https://doi.org/10.1634/theoncolog ist.2011-0210.

14. laccheri B, Fiore T, Cerquaglia A, Lupidi M, Cagini C. Transient therapeutic effect of vitrectomy in primary intraocular lymphoma. Int Ophthalmol. 2017;37:1333-5. https://doi.org/10.1007/s10792-016-0405-2.

15. Venkatesh P, Gogia V, Khanduja S, Gupta S, Kumar L, Garg S. Therapeutic vitrectomy for vitreal recurrence of intraocular lymphoma resistant to intravitreal methotrexate post systemic chemotherapy. J Cancer Res Ther. 2015;11:668. https://doi.org/10.4103/0973-1482.140824.

16. Gupta M, Han JJ, Stenson M, Maurer M, Wellik L, Hu G, et al. Elevated serum IL-10 levels in diffuse large B-cell lymphoma: a mechanism of aberrant JAK2 activation. Blood. 2012;119:2844-53. https://doi.org/10.1182/ blood-2011-10-388538.

17. Trittibach P, Barker SE, Broderick CA, Natkunarajah M, Duran Y, Robbie $\mathrm{SJ}$, et al. Lentiviral-vector-mediated expression of murine IL-1 receptor antagonist or IL-10 reduces the severity of endotoxin-induced uveitis. Gene Ther. 2008:15:1478-88. https://doi.org/10.1038/gt.2008.109.

18. Echeverry S, Shi XQ, Rivest S, Zhang J. Peripheral nerve injury alters blood-spinal cord barrier functional and molecular integrity through a selective inflammatory pathway. J Neurosci. 2011;31:10819-28. https:// doi.org/10.1523/JNEUROSCI.1642-11.2011.

19. Cassoux N, Giron A, Bodaghi B, Tran TH, Baudet S, Davy F, et al. IL-10 measurement in aqueous humor for screening patients with suspicion of primary intraocular lymphoma. Investig Ophthalmol Vis Sci. 2007:48:3253-9. https://doi.org/10.1167/iovs.06-0031.

20. Fisson S, Ouakrim H, Touitou V, Baudet S, Ben Abdelwahed R, Donnou $S$, et al. Cytokine profile in human eyes: contribution of a new cytokine combination for differential diagnosis between intraocular lymphoma or uveitis. PLoS ONE. 2013;8:e52385. https://doi.org/10.1371/journ al.pone.0052385.

21. Caraballo JN, Snyder MR, Johnston PB, O'Neill BP, Raja H, Balsanek JG, et al. Vitreoretinal lymphoma versus uveitis: cytokine profile and correlations. Ocul Immunol Inflamm. 2014;22:34-41. https://doi.org/10.3109/09273 948.2012.752507.

22. Raja H, Snyder MR, Johnston PB, O'Neill BP, Caraballo JN, Balsanek JG, et al. Effect of intravitreal methotrexate and rituximab on interleukin-10 levels in aqueous humor of treated eyes with vitreoretinal lymphoma. PLoS ONE. 2013;8:e65627. https://doi.org/10.1371/journal.pone.0065627.

23. Davis JL, Viciana AL, Ruiz P. Diagnosis of intraocular lymphoma by flow cytometry. Am J Ophthalmol. 1997;124:362-72.

24. Mayo Medical Laboratories. Leukemia/lymphoma immunophenotyping by flow cytometry—Mayo Medical Laboratories. 2016. http://www. mayomedicallaboratories.com/test-updates/attachment.php?id=41820.

25. Raja H, Salomao DR, Viswanatha DS, Pulido JS. Prevalence of Myd88 L265p mutation in histologically proven, diffuse large B-cell vitreoretinal lymphoma. Retina. 2016;36:624-8. https://doi.org/10.1097/IAE.00000 00000000996. 
26. Pulido JS, Raja H, Vile RG, Salomao DR, Viswanatha DS. Mighty MyD88 in health and disease. Retina. 2016;36:429-31. https://doi.org/10.1097/ IAE.0000000000000921.

27. Pulido JS, Salomao DR, Frederick LA, Viswanatha DS. MyD-88 L265P mutations are present in some cases of vitreoretinal lymphoma. Retina. 2015;35:624-7. https://doi.org/10.1097//AE.0000000000000589.

28. Bonzheim I, Giese S, Deuter C, Susskind D, Zierhut M, Waizel M, et al. High frequency of MYD88 mutations in vitreoretinal B-cell lymphoma: a valuable tool to improve diagnostic yield of vitreous aspirates. Blood. 2015;126:76-9. https://doi.org/10.1182/blood-2015-01-620518.

29. MayoMedicalLaboratories. Test ID: BCGR_immunoglobulin gene rearrangement, blood-Mayo Medical Laboratories. 2017. https://www mayomedicallaboratories.com/test-catalog/Clinical+and+Interpreti ve/83123.

30. Cani AK, Hovelson DH, Demirci H, Johnson MW, Tomlins SA, Rao RC. Next generation sequencing of vitreoretinal lymphomas from small-volume intraocular liquid biopsies: new routes to targeted therapies. Oncotarget. 2017;8:7989-98. https://doi.org/10.18632/oncotarget.14008.

31. Nelson DF, Martz KL, Bonner H, Nelson JS, Newall J, Kerman HD, et al. Non-Hodgkin's lymphoma of the brain: can high dose, large volume radiation therapy improve survival? Report on a prospective trial by the Radiation Therapy Oncology Group (RTOG): RTOG 8315. Int J Radiat Oncol Biol Phys. 1992;23:9-17.

32. Batchelor T, Carson K, O'Neill A, Grossman SA, Alavi J, New P, et al. Treatment of primary CNS lymphoma with methotrexate and deferred radiotherapy: a report of NABTT 96-07. J Clin Oncol. 2003;21:1044-9. https:// doi.org/10.1200/JCO.2003.03.036.

33. Plotkin SR, Betensky RA, Hochberg FH, Grossman SA, Lesser GJ, Nabors $L B$, et al. Treatment of relapsed central nervous system lymphoma with high-dose methotrexate. Clin Cancer Res. 2004;10:5643-6. https://doi. org/10.1158/1078-0432.CCR-04-0159.

34. Abrey LE, Moskowitz CH, Mason WP, Crump M, Stewart D, Forsyth P, et al. Intensive methotrexate and cytarabine followed by high-dose chemotherapy with autologous stem-cell rescue in patients with newly diagnosed primary CNS Iymphoma: an intent-to-treat analysis. J Clin Oncol. 2003:21:4151-6. https://doi.org/10.1200/JCO.2003.05.024.

35. Illerhaus G, Marks R, Ihorst G, Guttenberger R, Ostertag C, Derigs G, et al. High-dose chemotherapy with autologous stem-cell transplantation and hyperfractionated radiotherapy as first-line treatment of primary CNS lymphoma. J Clin Oncol. 2006;24:3865-70. https://doi.org/10.1200/ JCO.2006.06.2117.

36. Akiyama $\mathrm{H}$, Takase $\mathrm{H}$, Kubo F, Miki T, Yamamoto M, Tomita M, et al. Highdose methotrexate following intravitreal methotrexate administration in preventing central nervous system involvement of primary intraocular lymphoma. Cancer Sci. 2016;107:1458-64. https://doi.org/10.1111/ cas. 13012.

37. Kim MM, Dabaja BS, Medeiros J, Kim S, Allen P, Chevez-Barrios P, et al. Survival outcomes of primary intraocular lymphoma: a single-institution experience. Am J Clin Oncol. 2016;39:109-13. https://doi.org/10.1097/ COC.0000000000000028.

38. Berenbom A, Davila RM, Lin HS, Harbour JW. Treatment outcomes for primary intraocular lymphoma: implications for external beam radiotherapy. Eye (Lond). 2007;21:1198-201. https://doi.org/10.1038/sj.eye.6702437.

39. Kaushik M, Pulido JS, Schild SE, Stafford S. Risk of radiation retinopathy in patients with orbital and ocular lymphoma. Int J Radiat Oncol Biol Phys. 2012;84:1145-50. https://doi.org/10.1016/j.jjrobp.2011.12.097.

40. Fishburne BC, Wilson DJ, Rosenbaum JT, Neuwelt EA. Intravitreal methotrexate as an adjunctive treatment of intraocular lymphoma. Arch Ophthalmol. 1997;115:1152-6.

41. Frenkel S, Hendler K, Siegal T, Shalom E, Pe'er J. Intravitreal methotrexate for treating vitreoretinal lymphoma: 10 years of experience. $\mathrm{Br} J$ Ophthalmol. 2008;92:383-8. https://doi.org/10.1136/bjo.2007.127928.

42. Kitzmann AS, Pulido JS, Mohney BG, Baratz KH, Grube T, Marler RJ, et al. Intraocular use of rituximab. Eye (Lond). 2007;21:1524-7. https://doi. org/10.1038/sj.eye.6702804.

43. Agarwal A, Sadiq MA, Rhoades WR, Jack LS, Hanout M, Bierman PJ, et al. Combined systemic and ocular chemotherapy for anterior segment metastasis of systemic mantle cell lymphoma. J Ophthalmic Inflamm Infect. 2015;5:30. https://doi.org/10.1186/s12348-015-0060-1.

44. Abusamra K, Oray M, Ebrahimiadib N, Lee S, Anesi S, Foster CS. Intraocular lymphoma: descriptive data of 26 patients including clinico-pathologic features, vitreous findings, and treatment outcomes. Ocul Immunol Inflamm. 2016. https://doi.org/10.1080/09273948.2016.1193206.

45. Larkin KL, Saboo US, Comer GM, Forooghian F, Mackensen F, Merrill P, et al. Use of intravitreal rituximab for treatment of vitreoretinal lymphoma. Br J Ophthalmol. 2014;98:99-103. https://doi.org/10.1136/bjoph thalmol-2013-304043.

46. Montemurro M, Kiefer T, Schuler F, Al-Ali HK, Wolf HH, Herbst R, et al. Primary central nervous system lymphoma treated with high-dose methotrexate, high-dose busulfan/thiotepa, autologous stem-cell transplantation and response-adapted whole-brain radiotherapy: results of the multicenter Ostdeutsche Studiengruppe Hamato-Onkologie OSHO53 phase II study. Ann Oncol. 2007;18:665-71. https://doi.org/10.1093/ annonc/mdl458.

47. Illerhaus G, Muller F, Feuerhake F, Schafer AO, Ostertag C, Finke J. Highdose chemotherapy and autologous stem-cell transplantation without consolidating radiotherapy as first-line treatment for primary lymphoma of the central nervous system. Haematologica. 2008;93:147-8. https://doi. org/10.3324/haematol.11771.

48. Soussain C, Hoang-Xuan K, Taillandier L, Fourme E, Choquet S, Witz F, et al. Intensive chemotherapy followed by hematopoietic stem-cell rescue for refractory and recurrent primary CNS and intraocular lymphoma: Societe Francaise de Greffe de Moelle Osseuse-Therapie Cellulaire. J Clin Oncol. 2008;26:2512-8. https://doi.org/10.1200/JCO.2007.13.5533.

49. Soussain C, Choquet S, Fourme E, Delgadillo D, Bouabdallah K, Ghesquieres $\mathrm{H}$, et al. Intensive chemotherapy with thiotepa, busulfan and cyclophosphamide and hematopoietic stem cell rescue in relapsed or refractory primary central nervous system lymphoma and intraocular lymphoma: a retrospective study of 79 cases. Haematologica. 2012;97:1751-6. https://doi.org/10.3324/haematol.2011.060434.

50. Hoang-Xuan K, Bessell E, Bromberg J, Hottinger AF, Preusser M, Ruda $\mathrm{R}$, et al. Diagnosis and treatment of primary CNS lymphoma in immunocompetent patients: guidelines from the European Association for Neuro-Oncology. Lancet Oncol. 2015;16:e322-32. https://doi. org/10.1016/S1470-2045(15)00076-5.

51. Witzig TE, Vose JM, Zinzani PL, Reeder CB, Buckstein R, Polikoff JA, et al. An international phase II trial of single-agent lenalidomide for relapsed or refractory aggressive B-cell non-Hodgkin's lymphoma. Ann Oncol. 2011;22:1622-7. https://doi.org/10.1093/annonc/mdq626.

52. Nowakowski GS, LaPlant B, Macon WR, Reeder CB, Foran JM, Nelson $\mathrm{GD}$, et al. Lenalidomide combined with R-CHOP overcomes negative prognostic impact of non-germinal center B-cell phenotype in newly diagnosed diffuse large B-Cell lymphoma: a phase II study. J Clin Oncol. 2015;33:251-7. https://doi.org/10.1200/JCO.2014.55.5714.

53. Li Z, Qiu Y, Personett D, Huang P, Edenfield B, Katz J, et al. Pomalidomide shows significant therapeutic activity against CNS lymphoma with a major impact on the tumor microenvironment in murine models. PLoS ONE. 2013;8:e71754. https://doi.org/10.1371/journal.pone.0071754.

54. NIH-ClinicalTrials.gov. Pomalidomide and Dexamethasone in Treating Patients With Relapsed or Refractory Primary Central Nervous System Lymphoma or Newly Diagnosed or Relapsed or Refractory Intraocular Lymphoma. 2016. https://clinicaltrials.gov/ct2/show/NCT0172230 5?term $=$ pomalidomide+cns+lymphoma\&rank=1. Accessed $23 \mathrm{Nov}$ 2016.

55. Byrd JC, Furman RR, Coutre SE, Flinn IW, Burger JA, Blum KA, et al. Targeting BTK with ibrutinib in relapsed chronic lymphocytic leukemia. N Engl J Med. 2013;369:32-42. https://doi.org/10.1056/NEJMoa1215637.

56. Yang G, Buhrlage SJ, Tan L, Liu X, Chen J, Xu L, et al. HCK is a survival determinant transactivated by mutated MYD88, and a direct target of ibrutinib. Blood. 2016;127:3237-52. https://doi.org/10.1182/blood-201601-695098.

57. Treon SP, Tripsas CK, Meid K, Warren D, Varma G, Green R, et al. Ibrutinib in previously treated Waldenstrom's macroglobulinemia. N Engl J Med. 2015;372:1430-40. https://doi.org/10.1056/NEJMoa1501548.

58. Treon SP, Cao Y, Xu L, Yang G, Liu X, Hunter ZR. Somatic mutations in MYD88 and CXCR4 are determinants of clinical presentation and overall survival in Waldenstrom macroglobulinemia. Blood. 2014;123:2791-6. https://doi.org/10.1182/blood-2014-01-550905.

59. Wilson WH, Young RM, Schmitz R, Yang Y, Pittaluga S, Wright G, et al. Targeting B cell receptor signaling with ibrutinib in diffuse large B cell lymphoma. Nat Med. 2015;21:922-6. https://doi.org/10.1038/nm.3884. 
60. Ghesquieres H, Houillier C, Chinot O, Choquet S, Molucon-Chabrot C, Beauchene $\mathrm{P}$, et al. Rituximab-Lenalidomide (REVRI) in relapse or refractory primary central nervous system (PCNSL) or vitreo retinal lymphoma (PVRL): results of a "proof of concept" phase II study of the French LOC network (Abstract 785). Blood. 2016;128:785.

61. Bernard S, Goldwirt L, Amorim S, Brice P, Briere J, de Kerviler E, et al. Activity of ibrutinib in mantle cell lymphoma patients with central nervous system relapse. Blood. 2015;126:1695-8. https://doi.org/10.1182/blood -2015-05-647834.
62. Ahn IE, Jerussi T, Farooqui M, Tian X, Wiestner A, Gea-Banacloche J. Atypical Pneumocystis jirovecii pneumonia in previously untreated patients with CLL on single-agent ibrutinib. Blood. 2016;128:1940-3. https://doi. org/10.1182/blood-2016-06-722991.

63. Okamoto K, Proia LA, Demarais PL. Disseminated cryptococcal disease in a patient with chronic lymphocytic leukemia on ibrutinib. Case Rep Infect Dis. 2016;2016:4642831. https://doi.org/10.1155/2016/4642831.
Ready to submit your research? Choose BMC and benefit from:

- fast, convenient online submission

- thorough peer review by experienced researchers in your field

- rapid publication on acceptance

- support for research data, including large and complex data types

- gold Open Access which fosters wider collaboration and increased citations

- maximum visibility for your research: over $100 \mathrm{M}$ website views per year

At BMC, research is always in progress.

Learn more biomedcentral.com/submissions 